\title{
Examining Cross-Industry Collaboration in Sharing Economy Based On Social Exchange and Social Network Theories
}

\author{
Cheng-Wen Lee ${ }^{1}$ and Hao-Yuan $\mathrm{Yu}^{2}$
}

\begin{abstract}
Information technology and advanced online environments have reduced the cost of these exchange activities and triggered the emergence of the sharing economy. Con-sequently, public attitude toward the sharing economy has gradually shifted from re-luctance to acceptance. Moreover, the sharing economy has revolutionized the busi-ness models and viewpoints of conventional industries, and sharing service providers have gradually shifted from an independent to a collaborative stance, thereby affect-ing conventional economies. This study interprets the phenomenon of cross-industry collaboration in the sharing economy through social exchange and social network the-ories. A multiple-case research framework is used to examine tourism and service in-dustries. Secondary data of service providers and users on sharing platforms are ana-lyzed using content analysis, supplemented with a content analysis of the interview data of three hotel executives. The varying phenomena of the conventional and shar-ing economies on social exchange and social network were compared. Finally, this paper proposes conclusions and practical recommendations according to the analytical results.
\end{abstract}

JEL classification numbers: D85, M31, L14.

Keywords: Cross-Industry Collaboration, Sharing Economy, Social Exchange, Social Network.

\footnotetext{
${ }^{1}$ Department of International Business, Chung Yuan Christian University, Taoyuan City, Taiwan.

${ }^{2}$ College of Business, Chung Yuan Christian University, Taoyuan City, Taiwan.
} 


\section{Introduction}

Botsman is the thought leader of the sharing economy, which she defines as an economic model based on sharing underutilized assets, such as spaces, skills, and even tools, for monetary or nonmonetary benefits[1]. The network advantages in the Greater China region and its sufficient critical mass formed by its dense population enable more efficient resource allocation than do other regions[2]

However, other names and terms, such as collaborative economy and collaborative consumption, exist internationally because of varying sharing methods or new economic viewpoints[3]. A sharing economy reallocates the resources in an economic exchange system and facilitates $\mathrm{P} 2 \mathrm{P}$ collaborative consumption through methods, such as second-hand goods transactions, rental, and bartering, enabling the rights to use idle products or services[4][5]states that the embryonic form of the sharing economy dates back to the existence of sharing institutions before the emergence of capitalism and the operations of institutions, such as charities, religious groups, and production cooperatives, facilitating $\mathrm{P} 2 \mathrm{P}$ exchange of goods and services.

Stephany notes that the value of the sharing economy reflects the ability of a community to use underutilized assets through the Internet, thereby reducing the need for asset ownership[6]. People are reluctant to engage in collaborative consumption activities if the costs and potential risks of the exchange exceed the economic rewards[7]. Kim, Yoon, and Zo note that sharing platform providers or administrators who can maintain the rights of the exchanging parties can reduce people's perceived risks, and a reduced cost of loss favors people's intention to participate in collaborative consumption[8]. Additionally, collaborative consumption is a mutually beneficial exchange behavior, and community members expect to form a friendly and positive exchange relationship with each other to enable long-term stable development of the sharing platform[9] Therefore, the motive of the present study is inspired by the assumption that sharing economy platforms gradually increase interactions and form collaborative relationships with conventional economy platforms and existing tourism, hospitality, and transportation industries. By examining this assumption through the perspectives of social exchange theory (SET) and social network theory (SNT), the present study provides an understanding of the prospects of sharing economy development.

On the basis of the aforementioned research motive, the purpose of the present study is to apply SET and SNT to interpret the phenomenon of cross - industry collaborations in the sharing economy. Subsequently, the present study proposes opinions regarding the effect on the collaborating parties and both the theoretical and practical implications of the study. 


\section{Literature Review}

\subsection{Social Exchange Theory}

The most pivotal constructs of SET include exchange behaviorism [10], exchange structuralism [11], the Exchange Outcome Matrix [12], and the Exchange Network [13]. These sociologists' contributions to SET facilitate the vigorous development of modern SET. SET originates from numerous fields of study in the 1950s, such as anthropology[14][15], economics[16], behavioral psychology [17], and conflict sociology[18]. SET in economics is mainly influenced by classical economists, such as Adam Smith, David Ricardo, and John Stuart Mill, who adopt related concepts including profit, cost, transaction, and rational behavior. These economists have argued that in a free market, individuals rationally pursue to maximize material interests and utility in an exchange or trade with others, and this interpersonal interaction is considered a rational behavior of calculating the gains and losses. SET examines the motive of exchanging; most exchanges stem from unequal resource allocation.

\subsection{Social Network Theory}

The concept of social network was first proposed by Alfred Radcliffe- Brown, a renowned English anthropologist, in his study of social network structure. He focuses on the network concept of how culture defines behaviors of members in a boundary group such as tribe and village[19]. However, the actual interpersonal behaviors are far more complex than Radcliff-Brown's research that is relatively simple. Knoke and Kuklinski argue that a network is a specific linkage of people, objects, and events, and a relationship is the central concept of network analysis[20]. Network linkage varies by type of relationships. Common relationships include kinship, buyer-seller relationship, and organizational hierarchy. These relationships collectively form a social structure known as a social network [21].

Emirbayer and Goodwin define a social network as a set of social relationships connecting groups of individuals[22]. Therefore, the core objects discussed in SNT are the "relationships" formed by individuals rather than the individuals themselves. This viewpoint has also influenced the development of SNT and the basic assumptions in empirical research. SNT observes from mainly two major viewpoints, namely, an ego-centric and a socio-centric viewpoint[23].

\section{Research Methodology and Framework}

The present study uses this research method and applies SET and SNT to conduct an in-depth assessment of cross-industry collaborations in a sharing economy. This section describes the design and development of the research framework according to the predetermined research objective and questions. Therefore, the present study explores the operation of the collaboration between the sharing economy and conventional industries. Figure 1 illustrates the research framework of the present study. 
Sharing economy services

Accommodation platform

Transportation platform

Dining platform

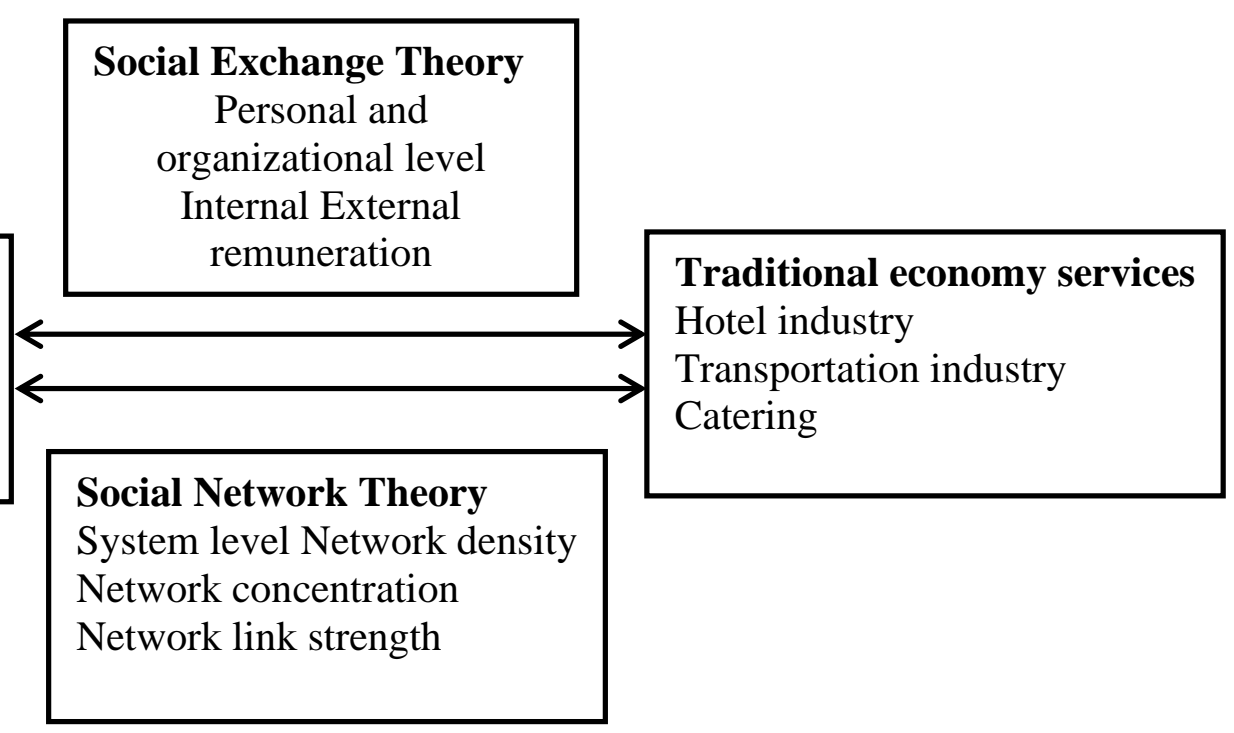

Figure 1: Conceptual Framework

Yin states that the three types of validity in a case study comprise construct, internal, and external validity [24]. In the present study, the construct validity is based on the deductive reasoning from SET and SNT. Regarding internal validity, various data sources are first collected. For example, the data for Case 1 comprised 2,000 reviews of service providers (i.e., landlords) and tenants between January and April 2017. The present study then identifies faithful reviews posted on the sharing economy platform by representative service providers (i.e., positively received landlords) and tenants receiving $\geq 3$ services and performs data analysis and extraction. The extracted data are then used to construct the internal validity of the present study. By contrast, the external validity is the degree to which the research outcomes can be applied to other scenarios. Through abundant and detailed descriptions, the present study elevates the generalizability of the research outcomes.

\section{Case Study}

According to the research objective, this study identifies the companies involved in existing cases of cross- industry collaboration between the sharing economy and conventional industries. The eligible sharing economy firms must meet the following four criteria: (a) developed under an excellent social credit system with a comprehensive payment system; (b) based in a country with a gross domestic product per capita of $\geq \mathrm{US} \$ 10,000$; (c) established in a society where flexible scheduling is highly sought after; and (d) employment freedom that enables profitability while having fun. The development of the sharing economy must seamlessly integrate these four factors at an institutional level to achieve effective innovation and healthy development. This study seeks suitable cases according to the aforementioned criteria. 
Case 1: At least 100 lodgings will be installed with electric car chargers in an Airbnb-Tesla collaboration. In August 2015, Tesla provided free electric car chargers to upscale lodgings with $\geq 4$-star ratings and $\geq 5$ rooms that were listed on Airbnb and reviewed by Tesla. After installation, Airbnb listed the lodgings with Tesla-compatible charging stations on their official website.

SET analysis: Tesla needed to strengthen their intrinsic rewards and brand trust in order to enhance marketing exposure of their new car models, namely, Model 3 (a four-door budget sedan) and Model X (a sport utility vehicle). Therefore, the partnership relies on Airbnb's reputation to publicize Tesla's charging facilities. This collaboration not only enables Tesla to expand their penetration rate for charging stations but also incentivizes landlords to purchase their own electric cars and rent them as a package. Additionally, Tesla can promote the auto-drive functions to Airbnb tenants who may be potential buyers of electric vehicles. The collaboration is a mutually beneficial arrangement for both companies involved.

SNT analysis: The partnership between Tesla and Airbnb is a strong tie. Because the charging stations are considered specific assets, Tesla must install charging stations extensively. Moreover, luxury lodgings listed on Airbnb have available space for free charging stations. The partnership may even encourage the landlords to collectively purchase electric cars from Tesla for rental to their tenants. Therefore, this study infers that the collaboration between these two companies will become increasingly close and focused.

Case 2: Airbnb partners with Delta, Qantas, and Virgin America; Uber co-operates with Starwood Hotels and Resorts Worldwide

Airbnb announced its collaborations with Qantas and Virgin America in November 2015 and March 2016, respectively. Airbnb customers may now earn air miles for the aforementioned airlines by booking their accommodation through Airbnb. Starwood Hotels and Resorts Worldwide and Uber announced their partnership in February 2015. Starwood Preferred Guests may earn additional Starpoints when they use Uber services anywhere in the world.

SET analysis: Conventional hotels and resorts have long used mileage programs to attract travelers. From Delta's SkyMiles, enrolled members have earned mileage points from conventional accommodation services for years. Therefore, Airbnb is merely a new partner for Delta, and the mileage-accumulation mechanism is not remarkably different from Delta's collaborations with conventional hotels. By contrast, Starwood customers may ride with either conventional taxicabs or Uber as their transportation means from and to their hotels. In this partnership, both Starwood and Uber offer their customers an additional option to earn points. Therefore, both the Delta-Airbnb and Starwood-Uber collaborations are considered weak ties.

SNT analysis: Both of the aforementioned examples are weak ties because Airbnb partnered with multiple airlines rather than exclusively with a single one. Additionally, Airbnb currently lists rooms in 65,000 cities in 191 countries, and the airline partners must provide frequent flights and extensive destinations to satisfy customers' needs. If Airbnb enables its customers to book flight tickets and lodgings 
with a one-stop service (i.e., a package of flight tickets from partnered airlines and rooms listed on Airbnb), this study would consider Airbnb's partnership with airlines a strong tie.

Case 3: Airbnb collaborates with local travel guides and launches 3- to 5-day trips Travelers can now book not only their lodgings but also various travel experiences such as gourmet events, cultural events, entertainment, sports, music, fashion, health, and outdoor activities on Trips, a new function on Airbnb's homepage. Airbnb has evolved from a short-stay rental platform to a comprehensive travel platform overnight. In fact, Airbnb has long planned to expand its business model to encompass all tourism aspects because tourism is a major market long due for a revolutionary change.

SET analysis: Airbnb provides customers with unique local travel experiences guided by local guides. In contrast to sightseeing tours provided by conventional travel agencies, Airbnb enhances customer stickiness by offering customers with different value and experience. The new service enables Airbnb customers to exchange with local guides and gain additional value out of their trips.

SNT analysis: Airbnb's collaboration with local travel guides offers opportunities for in-depth travel arrangements on their homepage in addition to the existing lodging function. The partnership not only strengthens Airbnb's ties with local hosts and travel guides but also increases the recreational value of the destination in question. Therefore, the tie will become increasingly strong and close.

Case 4: Airbnb transforms to a one-stop shop with investment in restaurant reservation app Resy and new function Flights

In January 2017, Airbnb announced its investment in Resy, a restaurant reservation mobile app that focuses on upscale restaurants. Airbnb expects to precisely assess diners' preferences and attract revisits in the future. Additionally, Airbnb launched the flight-booking service Flights to herald its transformation from a short-stay rental service to a one-stop shop for travelers.

SET analysis: Airbnb extends its service to restaurant reservation to provide local gourmet options before further extending to flight-booking services. Airbnb customers can now book multiple reservations in one transaction, resulting in increased customer stickiness and additional value for the exchanging service.

SNT analysis: By extending its service to restaurant and flight reservation, Airbnb strengthens its ties with local hosts, travel guides, and restaurants. The collaboration increases the attractiveness of the destination in question and strengthens the ties of all parties involved.

According to the viewpoint in the present study, in a sharing economy, collaboration is not a new economic activity. It is merely the absence of exchange platforms in the past that led to the uncovering of certain previously undiscovered sharing needs or those needs that were realized in conventional B2C models instead. Once the sharing platforms begin to provide useful information, supply and demand of these needs manifest in the form of a sharing economy. The collaborations offer local and personalized travel experience. This business model not only provides consumers with diversified options but also expands business opportunities for the subject 
company, thus enabling it to build its own tourism empire.

\section{Secondary Data Analysis}

The data source in this study is regarded as a library case. This section lists the data obtained from travel blogs posted by Airbnb hosts, travel guides (i.e., travel service providers), and service recipients. Table 1 shows the representative search data screened by this study in accordance with data validity and reliability.

Table 1: Case information

\begin{tabular}{|c|c|c|c|}
\hline $\begin{array}{c}\text { Case information } \\
\text { to obtain identity }\end{array}$ & $\begin{array}{c}\text { Rating } \\
\text { Number }\end{array}$ & $\begin{array}{c}\text { Recommended } \\
\text { number }\end{array}$ & Content description \\
\hline Good landlord & 400 or more & More than 10 people & $\begin{array}{c}\text { At least } 10 \text { trips } \\
\text { The reply rate is above } \\
90 \%\end{array}$ \\
\hline Tenant status & $\begin{array}{c}3 \text { times or } \\
\text { more }\end{array}$ & More than 3 people & $\begin{array}{c}\text { The landlord evaluates to } \\
\text { fine tenants for more than } \\
2 \text { times }\end{array}$ \\
\hline Experience expert & $\begin{array}{c}\text { More than } 30 \\
\text { times }\end{array}$ & More than 30 people & $\begin{array}{c}\text { Unique experience time } \\
\text { more than } 3 \text { hours } \\
\text { More than } 3 \text { experiences } \\
\text { in } 2 \text { days } \\
\text { There are more than } 500 \\
\text { visits in a week }\end{array}$ \\
\hline
\end{tabular}

The aforementioned reviews provide three perspectives from landlords, tenants, and experience hosts for analyzing cross-industry collaboration in the sharing economy. Cross-industry collaboration enables each party to enter the field of travel planning and become a part of the travel package platform encompassing lodging, itineraries, car rental, and restaurants. Additionally, cross-industry collaboration facilitates comprehensive local travel services so that travelers no longer have to overschedule their itineraries. Once they book their flight tickets, lodgings, and restaurants, local guides take over the remaining activities for a cozy and fun in-depth tour. The rich cultural feast provides unique and unforgettable experiences and memories for the tourists. Users of these packaged services are more concerned about the experience rather than convenience. These users demand a networked service similar to the concept of a service ecosystem. If Airbnb can increase the ratio of real-time room availability by integrating with other online travel agencies such as Expedia and TripAdvisor, the present study assumes that business hotel operators may recognize Airbnb as a cross-industry competitor not to be ignored in addition to competition from existing competition with other hotel operators.

The collaborations offer local and personalized travel experience. This business model not only provides consumers with diversified options but also expands 
business opportunities for the subject company, thus enabling it to build its own tourism empire. Table 2 summarizes the comparison results of the three case studies examined in this study.

Table 2: Comparative Study

\begin{tabular}{|c|c|c|c|c|c|}
\hline \multicolumn{2}{|c|}{ Case name } & $\begin{array}{c}\text { Airbnb versus } \\
\text { Tesla }\end{array}$ & $\begin{array}{c}\text { Airbnb aviation } \\
\text { industry } \\
\text { Uber with } \\
\text { Starwood }\end{array}$ & $\begin{array}{c}\text { Airbnb versus } \\
\text { Trips }\end{array}$ & $\begin{array}{c}\text { Airbnb versus } \\
\text { Resy Flights }\end{array}$ \\
\hline \multirow{2}{*}{ cooperation method } & $\begin{array}{c}\text { Create new } \\
\text { types of } \\
\text { services }\end{array}$ & $\begin{array}{c}\text { Cross-industry } \\
\text { exchange bonus } \\
\text { points }\end{array}$ & $\begin{array}{c}\text { Customers } \\
\text { niche parallel } \\
\text { extension } \\
\text { services }\end{array}$ & $\begin{array}{c}\text { Customers } \\
\text { niche extends } \\
\text { back service }\end{array}$ \\
\hline $\begin{array}{c}\text { Society } \\
\text { exchange } \\
\text { views }\end{array}$ & Power relations & Balance & Balance & Rely & Rely \\
\cline { 2 - 7 } & The movement & Configuration & Configuration & Flow & Flow \\
\hline $\begin{array}{c}\text { Social networkes } \\
\text { view }\end{array}$ & Concentration & Diffusion & Diffusion & Configuration & Configuration \\
\cline { 2 - 7 } & Central location & Social-center & Social-center & Self-center & Self-center \\
\cline { 2 - 7 } & Link strength & Weak link & Weak link & Strong link & Strong link \\
\hline
\end{tabular}

The left half of Figure 2 demonstrates that Airbnb is currently setting up a joint agency representing services in the sharing economy. Airbnb first strengthens the user's confidence and trust through social exchange. In a sharing economy, trust is the key to success and is the basis of the spirit of sharing. Therefore, the accumulated online reviews from users represent the most pivotal asset for Airbnb. Subsequently, this study constructs the centrality and central points of the network on the right half of Figure 2 to represent the increased collective bargaining power of the integrated service. The collaboration not only coordinates the development and operation of each sharing and conventional economic platform but also establishes service standards through self-discipline (Figure 2). 

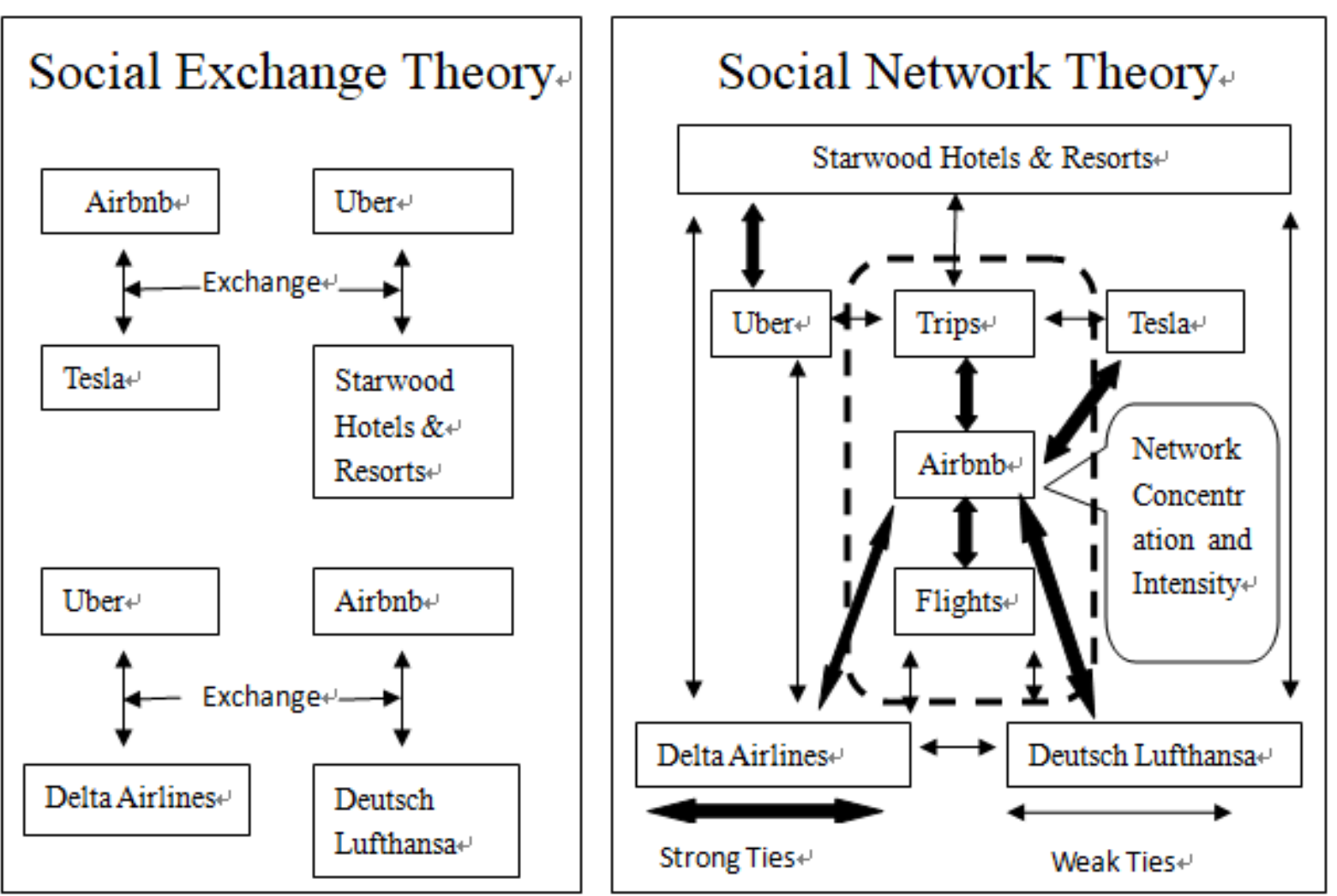

Figure 2: Cases analyzed through SET and SNT

Figure 3 illustrates the conventional economy portion of the cross-industry collaboration and demonstrates the concept of interregional integration. Through interregional integration, the characteristics of regional tourism and marketing highlights are enhanced. The improved regional tourism service and environment develop into unique, topical, and characteristic horizontal integration of the tourism and recreational highlights of related industries. Various attractions and industries are integrated to create added value and additional benefits and satisfy domestic and foreign tourists' needs through improved infrastructure and service quality. Consequently, an attractive environment for international tourism is constructed to effectively increase domestic and foreign tourists' willingness to travel. However, a central node representing a social network phenomenon is absent; the structure represents a relatively fragmented network. Therefore, the conventional industries' attempt to integrate with sharing economy industries leads to forward and backward horizontal development, and the strength may vary, presenting clear differences. 


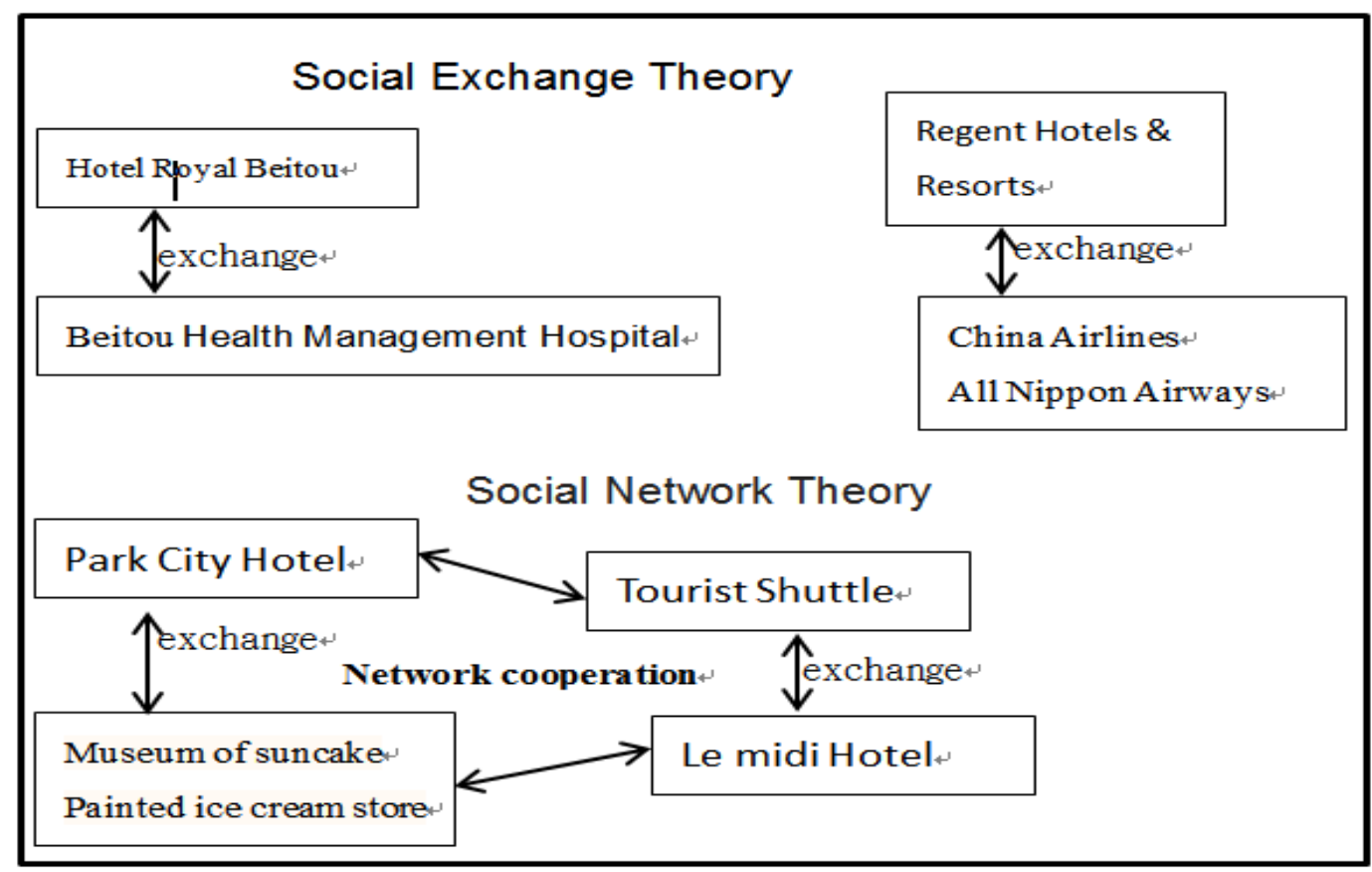

Figure 3: Traditional economic cross-industry cooperation

The aforementioned analysis of the difference between conventional economy and the sharing economy reveals that conventional economy features exclusivity in product usage, whereas the sharing economy does not generate resource competition because it uses idle resources. Therefore, in a sharing economy, the more utilized the resources are, the more added value the resources generate. For example, the formulation and improvement of a related database increases the spread of the sharing economy. Table 4 summarizes the difference between conventional economy and the sharing economy from the perspectives of SET and SNT. The two viewpoints reveal the differences between the two economy types. The sharing economy supplements what is overlooked in conventional economy and highlights the social cooperative relationships where economic benefit is not the top priority. Additionally, the sharing economy demonstrates the relationship between trust and commitment and the use of weak ties.

\section{Conclusions and Suggestions}

\subsection{Theoretical Implications}

The research outcomes of this study reveal that the sharing economy may attract some demand in a conventional economy system and influence small and mediumsized enterprises. However, because supporting measures, such as online media platforms and personal reputation records, must be constructed to operate a sharing economy, new jobs and development opportunities are created. Online platforms in 
sharing economies are constructed according to the services provided and how fees are charged, and the platforms can be categorized into free service-matching, transaction fee-based, and entirely for-profit platforms. The operation and business models of these three types may vary, but all exhibit opportunities for entrepreneurial development. The collaboration between the sharing economy and conventional economy has just begun and is expected to lead to more innovations during the developmental process.

Both conventional and sharing economy systems can coexist. Although the sharing economy affects the conventional economic models (e.g., shift in market demand), it creates new business opportunities during the diverse developmental process. Regardless of business scale, companies should acknowledge the influence of collaborative consumption on past vertical operations. The questions that must be tackled include how the sharing economy threatens or enhances conventional business activities, how to attract engagement from employees, customers, and other business partners, and the possibility of stimulating the opportunities and demand of innovative services through a sharing economic model.

Therefore, the accumulated online reviews from users represent the most pivotal asset. However, developmental conditions for the sharing economy, such as trust and commitment, are not always present due to cultural and lifestyle differences. The sharing economy is more likely to grow in a mature society or culture. Otherwise, the development may be challenging.

\subsection{Practical Implications}

Rogers suggests in Diffusion of Innovations that weak and strong ties are regarded as heterogeneous and homogenous links, respectively. Heterogeneous elements are difficult to link but exhibit a greater effect on diffusion than the homogenous links do[25]. Therefore, future studies can examine the motives and methods for the diffusion of weak ties and interpret the benefits of the collaboration in weak ties[25]. This study reveals that the vulnerability of weak ties is not entirely attributed to difficulty in communication between the heterogeneous elements. The greatest difference between strong and weak ties is that the strong ties are formed through their relative distance, whereas the weak ties are mostly linked voluntarily. Therefore, entrepreneurs' dream of starting a business is the real source that triggers the linking of two weak elements. Additionally, the bridging characteristics of weak ties transmit rare information and generate newsonomics, thereby achieving more extensive ties.

Incorporating SET and SNT into studies on sharing economy is currently still in a beginning stage, and numerous research directions are available for future studies. For example, industrial difference and the correlation between social networks and business performance can be explored in future research. 


\section{References}

[1] Botsman, R. (2013). The Sharing Economy Lacks A Shared Definition.

Retrieved from Fastcoexist Website:

http://www.fastcoexist.com/3022028/the-sharing-economy-lacks-a-shareddefinition.

[2] Dillahunt, T. R., \& Malone, A. R. (2015). The promise of the sharing economy among disadvantaged communities. In Proceedings of the 33rd Annual ACM Conference on Human Factors in Computing Systems, 2285-2294.

[3] Owyang, J., Samuel, A. \& Grenville, A. (2014). Sharing is the New Buying: How to Win in the Collaborative Economy. Vision Critical and Crowd Companies Report.

[4] Belk, R. (2014). You are what you can access: Sharing and collaborative consumption online.Journal of Business Research, 67(8). 1595-1600.

[5] Rifkin, J. (2014). The Zero Marginal Cost Society : The Internet of Things, the Collaborative Commons, and the Eclipse of Capitalism, New York: St. Martin's Press.

[6] Stephany, A.( 2015). The Business of Sharing: Making it in the New Sharing Economy. London,United Kingdom: Palgrave Macmillan.

[7] Hamari, J., Sjöklint, M., \& Ukkonen, A. (2015). The sharing economy: Why people participate in collaborative consumption. Journal of the Association for Information Science and Technology, 67(9), 2047-2059. [22] Rogers, E. M. (2003), Diffusion of Innovations (5th ed.), New York: Free Press.

[8] Kim, J., Yoon, Y., \& Zo, H. (2015). Why people participate in the sharing economy: A social exchange perspective, In PACIS 2015 proceedings. Paper 76.

[9] Albinsson, P. A., \& Yasanthi, P. B. (2012). Alternative marketplaces in the 21st century: Building community through sharing events. Journal of consumer Behaviour, 11(4). 303-315.

[10] Homans, G.C. (1958). Social Behavior as Exchange. The American Journal of Sociology. 63, 597-606.

[11] Blau, P. M. (1964). Exchange and Power in Social life, New York: John Wiley and Sons.

[12] Kelley, H. H., \& Thibaut, J. W. (1978). Interpersonal relations: A theory of interdependence, New York: Wiley.

[13] Emerson, R. M. (1987). Toward a theory of value in social exchange. In K. S. Cook (Ed.), Social exchange theory. 11-46. Newbury Park, CA: Sage.

[14] Levi-Strauss, C. (1969). The Elementary Structures of Kinship, Boston: Beacon Press.

[15] Mauss, M. (1954). The Gift: Forms and Functions of Exchange in Archaic Societies. Translated by Ian Cunnison. Glencoe: Free Press.

[16] Ekeh, P. P. (1974). Social exchange theory: The two traditions. Cambridge, MA: Harvard University Press. 
[17] Skinner, B.F. (1983). A Matter of Consequences. Alfred A. Knopf, New York, 323.

[18] Collins, R. (1975). Conflict sociology: Toward an explanatory science. Academic Pr.

[19] Brown R. (1951). The Comparative Method in Social Anthropology. Journal of the Royal Anthropological Institute of Great Britain and Ireland, 81(1/2), $15-22$.

[20] Knoke, D., \& Kuklinski J. (1982). Network Analysis, Beverly Hills: Sage Publications.

[21] Adler, P. S., \& Kwon, S. W. (2002). Social Capital: Prospects for a New Concept. Academy of Management Review, 27, 17-40.

[22] Emirbayer, M., \& Goodwin, J. (1994). Network analysis, culture, and the problem of agency. American Journal of Sociology, 99. 1411-1454.

[23] Garton, L., Haythornthwaite, C., \& Wellman, B. (1997). Studying online social networks. Journal of Computer-Medicated Communication,3(1)

[24] Yin, R. K.( 2009). Case study research: Design and methods (4th ed.). Thousand Oaks, CA: Sage.

[25] Rogers, E. M. (2003), Diffusion of Innovations (5th ed.), New York: Free Press. 